\title{
DESIGN PEDAGÓGICO DE RECURSOS EDUCACIONAIS ABERTOS EM AMBIENTE VIRTUAL
}

\author{
ELENA MARIA MALLMANN
}

Pós-doutora em Educação, professora adjunta do Departamento de Adminstração Escola do Centro de Educação da Universidade Federal de Santa Maria. E-mail: elena.ufsm@gmail.com

JULIANA SALES JACQUES

Doutoranda em Educação, professora substituta do Departamento de Metodologia do Ensino do Centro de Educação da Universidade Federal de Santa Maria.E-mail: elena.ufsm@gmail.com

\begin{abstract}
RESUMO
Analisamos o impacto de Recursos Educacionais Abertos (REA) no Ambiente Virtual de EnsinoAprendizagem (AVEA) Moodle. Trata-se de resultado de transposição didática dos conteúdos programáticos de disciplinas mediadas por tecnologias educacionais em rede no ensino superior. A preocupação temática multidisciplinar foi avaliar se o design pedagógico de REA maximiza acoplamento hipermidiático entre recursos e atividades de estudo semanais. A tipologia teóricometodológica de pesquisa-ação configurou-se em ciclos de planejamento, registros e reflexão crítico-interpretativa refinados pela aplicação de questionários survey ordenados por escala Lickert. Como resultado, destacamos a fluência tecnológico-pedagógica como saber necessário à performance docente durante programação de recursos didáticos e atividades de estudo digitais. Registramos inovações didáticas baseadas em transformações e regularidades nas ferramentas recursos e atividades. Concluímos que a elaboração de REA como referenciais didáticos (modelos e exemplares) amplia fluência tecnológico-pedagógica de professores e estudantes universitários nas tecnologias contemporâneas, maximizando interatividade e interação em plataformas institucionais.
\end{abstract}

Palavras-chave: Tecnologia educacional. Fluência tecnológico-pedagógica. Recurso Educacional Aberto

\section{TEACHING DESIGN OF OPEN EDUCATIONAL RESOURCES IN A VIRTUAL ENVIRONMENT}

\begin{abstract}
We analyze the impact of Open Educational Resources (OER) in Teaching and Learning Virtual Environment (AVEA) Moodle. This is a result of didactic transposition of the syllabus subjects mediated by educational technology network in attendance and distance modalities. The multidisciplinary thematic concern was to assess whether the REA pedagogical design maximizes coupling between hypermedia resources and weekly study activities in higher education. The theoretical-methodological type of research-action configured in planning cycles, records and critical-interpretative reflection refined by the application of survey questionnaires ordered by Likert scale. As a result, we emphasize improvement of technological and pedagogical proficiency in teaching performance during programming teaching resources and digital study activities. Recorded educational innovations based on changes and regularities in the tools and resources activities. We conclude that the development of OER as didactic references (models and copies) extends technological and pedagogical fluency of teachers and students in contemporary technology, maximizing interactivity and interaction in institutional platforms.
\end{abstract}

Keywords: Educational technology; Technological and pedagogical fluency; Open Educational Resource

\section{Introdução}


As tecnologias educacionais em rede, conhecidas em grande escala como tecnologias digitais, potencializam a flexibilização de práticas pedagógicas quando permitem interatividade com os conteúdos curriculares e interação colaborativa entre estudantes e professores. Para tanto, é necessário que as características da hipermídia educacional sejam contempladas na organização didático-metodológica dos pares de recursos didáticos e atividades de estudo digitais.

As versões mais atualizadas de Ambientes Virtuais de Ensino-Aprendizagem (AVEA), como a plataforma Moodle, permitem ampliar a integração das tecnologias em rede nas modalidades presencial e a distância, maximizando as práticas de interatividade e interação colaborativa. Diante disso, requer-se, de professores e estudantes, desenvolvimento e ampliação de fluência tecnológicopedagógica nas habilidades contemporâneas, nos conceitos fundamentais e nas capacidades intelectuais. É por isso que nossa preocupação temática insere-se no campo da pesquisa-ação multidisciplinar com foco na avaliação do impacto de uma solução educacional (design pedagógico) planejada e disponibilizada à comunidade universitária. Essa solução foi criada como um conjunto de Recursos Educacionais Abertos $\left(\mathrm{REA}^{1}\right)$ e é denominado, por nós, de Disciplina-Exemplo no Moodle. A estruturação didático-metodológica caracteriza-se como exemplar que potencializa acoplamento hipermidiático entre recursos e atividades de estudo semanais.

Nesse contexto, inicialmente, argumentamos sobre o potencial da integração das tecnologias digitais contemporâneas na educação presencial, a distância e eLearning. Desdobramos os princípios e os conceitos do desenvolvimento e da ampliação da fluência tecnológico-pedagógica que, na realização da transposição didática dos conteúdos programáticos do ensino superior, apresenta-se como saberes necessários à performance docente.

Em sequência, detalhamos o modelo teórico-prático como design pedagógico de recursos e atividades de estudo hipermidiáticos em AVEA. Explicitamos a abordagem teórico-metodológica e os procedimentos de pesquisa-ação como dinâmica prospectiva e retrospectiva do trabalho em equipe multidisciplinar. Apresentamos análise do conjunto de REA na Disciplina-Exemplo como resultado concreto de solução educacional mediada por tecnologia, planejada e implementada no âmbito institucional para melhoria nos índices de fluência tecnológico-pedagógica na realização da transposição didática dos conteúdos programáticos do ensino superior. Por fim, concluímos argumentando que a elaboração de REA como referenciais didáticos (modelos e exemplares) amplia

\footnotetext{
1 Butcher, Kanwar e Uvalic - Trumbic - (2011) explicam que REA são materiais em qualquer suporte ou mídia que estão sob domínio público ou estão licenciados de maneira aberta para que possam ser utilizados e/ou adaptados. Os REA são inovadores do ponto de vista da movimentação de conceitos e práticas abertas, especialmente, por estarem atrelados à transparência e à promoção do compartilhamento do conhecimento (AMIEL, 2012; UNESCO, 2011).

Nota:

1. Apoio Financeiro: Capes - Bolsa de Doutorado - Demanda Social
} 
a fluência de professores e estudantes universitários nas tecnologias contemporâneas, maximizando interatividade e interação em AVEA institucionais.

\section{Integração das tecnologias educacionais em rede na educação presencial, a distância e eLearning}

A atualização dos componentes de hardware e software no campo da produção tecnológica é rápida, o que gera impactos sociais e econômicos acelerados, tanto do ponto de vista da divulgação da informação quanto da comunicação. No contexto escolar, os debates sobre os efeitos dessas contínuas transformações na sociedade contemporânea tornam-se cada vez mais urgentes. É certo que a história da educação está repleta de exemplares que comprovam a presença das tecnologias como ferramentas de suporte aos processos de ensinar e aprender. Esse é o caso de ferramentas como os quadros e os livros didáticos impressos, por exemplo. A codificação da linguagem e seus mecanismos tecnológicos de reprodução, em grande escala, são alicerces da arquitetura educacional, visível tanto nos aspectos do patrimônio logístico (prédios) quanto nos aspectos processuais dos atributos e funções de professores e estudantes. A natureza do trabalho docente pode ser compreendida, ao longo da história da educação formal, pelo papel do professor em sala de aula no que se refere aos seus afazeres apoiados em diversas tecnologias e as técnicas à elas associadas.

Mantendo a reflexão na contemporaneidade, percebemos que compreender a criação e o compartilhamento digital, síncrono e assíncrono, que vivenciamos nas últimas décadas requer critérios e princípios bastante sistemáticos. Se as tecnologias contemporâneas de informação e comunicação digitais têm "força" para modificar as relações pessoais, socioculturais e trabalhistas, elas têm "força" para modificar as relações estabelecidas entre os mediadores escolares (professores e estudantes)? Poderíamos desdobrar essa pergunta em vários pontos de análise criteriosa, estabelecendo temáticas de pesquisa. Porém, preocupamo-nos atualmente em criar condições para compreender o alcance efetivo, em termos de inovação científico-tecnológica e didáticometodológica, das tecnologias em rede no campo educacional. Assim, visando sistematização e proposição de soluções, capazes de modificar práticas de professores e estudantes, delimitamos nosso foco de pesquisa nas condições requeridas dos professores para integrar tecnologias educacionais ao processo ensino-aprendizagem.

Podemos, de fato, afirmar que as tecnologias qualificam nossas possibilidades de raciocínio e apropriação de conhecimento, na medida em que modificamos as formas de interação. Do ponto de vista da comunicação social (redes sociais) mediada por tecnologias parece estar em curso um 
processo de redimensionamento das funções e dos papéis sociais das pessoas (Anderson e Dron, 2014). Com as ferramentas atuais da web 2.0, alteramos nosso status de meros espectadores para criadores de informação. Os movimentos de criação e disponibilização de novas ferramentas são impressionantes, se analisados do ponto de vista da criatividade humana e da preocupação em atender demandas em períodos cada vez menores. Um dos problemas associados a isso é a lógica altamente consumista atrelada à renovação dos estoques de produtos em oferta nas prateleiras, tanto presenciais quanto virtuais. Se, por um lado, essa efervescência gera e modela percursos de acesso mais rápido, por outro lado, evidencia questões como: temos avançando em termos de formação para a cidadania nos pilares de uma sociedade mais ética e mais democrática? Temos conseguido desenvolver a autonomia necessária para tomar decisões mais justas e coerentes a cada situação?

A escola é espaço para promoção do desenvolvimento de fluência em tecnologias, mas até que ponto temos consolidado os propósitos educacionais das políticas públicas que visam à formação para a criticidade? A quintessência da problematização em torno do potencial e do impacto das tecnologias em rede é avançar na compreensão do que podemos fazer se as tornamos como aliadas no processo educacional contemporâneo. Ao argumentarmos a favor da integração das tecnologias em rede na educação, amparamo-nos na fluência tecnológico-pedagógica (Kafai et. al., 1999) como condição sine qua non na performance docente.

A integração das tecnologias em rede ao processo ensino-aprendizagem permite criação de novas ideias, projetos e soluções (bens e serviços). A “colaboração em massa” (Tapscott e Williams, 2007) gera fluxos contínuos de informações que podem ser transformadas em conhecimento. O impacto das tecnologias no processo educacional pode ser tão significativo quanto no espectro econômico ou social, desde que professores desenvolvam fluência para produção, adaptação e compartilhamento de recursos didáticos, problematizando os conteúdos curriculares na perspectiva da educação como prática da liberdade (Freire, 1982;1989). A educação mediada por tecnologias em rede implica diálogo-problematizador como interação colaborativa, que produz como resultados aprendizagem e desenvolvimento psíquico-intelectual.

Com o advento das tecnologias digitais, como as ferramentas da Web 2.0, o leque de opções educacionais se ampliou, pois os mecanismos de interatividade e interação são muito mais compreensíveis. Dispositivos de hardware, como os mouses ou mesmo as telas sensíveis ao toque, tornam os softwares mais suscetíveis à manipulação. Operações inicialmente realizadas apenas via linhas de comando em terminais, hoje podem ser realizadas de modo gráfico. Um bom exemplo é a produção e a divulgação de informação em páginas na Internet, como os blogs, por exemplo. Para isso, não é necessário saber as operações de comando para programação em html porque oferecem 
editores de texto semelhantes entre si.

No contexto educacional, essa evolução tecnológica gerou possibilidades de inovação tecnológica, uma vez que as plataformas virtuais de gerenciamento de conteúdos e de aprendizagem permitiram agregar, numa mesma base tecnológica associada a sistemas de servidores e bancos de dados, opções de produção, disponibilização, comunicação, relatórios e estatísticas de acesso e ações realizadas pelos participantes cadastrados. Com tudo isso, evidenciamos que a produção e a publicação de informação tem aumentado consideravelmente. No entanto, está muito longe de se tornar conhecimento enquanto capacidade intelectual para compreensão dos fenômenos científiconaturais (física, química, biologia), sociais (psicologia, sociologia), econômicos (administração, contabilidade), jurídicos, ambientais, lógico-matemáticos (cálculos), ontológicos (filosofia, teologia), culturais (artes plásticas, dança, música, teatro, cinema) e pedagógicos (educação de crianças, jovens e adultos).

Castells (1999: 266) discute a sociedade informacional, do ponto de vista das modificações no mercado de trabalho, representando sinteticamente os cargos de desempenho de tarefas em tipologias:

[...] os trabalhadores ativos na rede, que estabelecem conexões por iniciativa própria e navegam pelas rotas da empresa em rede; os trabalhadores passivos na rede, que estão on-line, mas não decidem quando, como, por que ou com quem; os trabalhadores desconectados, presos a suas tarefas específicas, definidas por instruções unilaterais não interativas[...].

No viés interpretativo do autor, as formas complexas e diversas de trabalho estão atreladas, essencialmente, ao tipo de tarefas que cada um implementa e, certamente, ao nível de desenvolvimento e habilidades de cada um na manipulação das tecnologias em cada contexto. Essa tipologia pode ser aproveitada com facilidade para analisar as estabilidades, os avanços e/ou recuos no contexto educacional sob a ótica da integração das tecnologias, tanto na realização de tarefas burocráticas quanto pedagógicas.

$\mathrm{Na}$ história educacional, as tecnologias têm sido compreendidas em grande escala por dois pontos extremos. A perspectiva contemplativa ocasiona um obscurecimento (Latour, 2001), já que as funcionalidades são compreendidas por poucas pessoas de formação técnica. Isso gera uma atmosfera de atributos mágicos obstaculizando o potencial de alcance em termos de resultados concretos nas práticas escolares. Esse é o campo dos trabalhadores passivos e desconectados referenciados por Castells (1999). Já do ponto de vista tecnicista, as tecnologias são deterministas e fixam valores imediatos para os empreendimentos. Nesse caso, normalmente, tecnologias e técnicas 
são confundidas. Por mais que exista conexão, a passividade é visível, porque os determinantes não são claramente analisados e compreendidos por todos os que utilizam as tecnologias para cumprir suas tarefas. Diante disso, questionamo-nos: como avançar para a ativação na rede de tal modo que o trabalho realizado por cada um gere conhecimento e autonomia para mobilizar conexões e, por consequência, cocriação?

Visto isso, argumentamos a favor da integração das tecnologias educacionais em rede nas modalidades presencial, a distância e eLearning. Para tanto, apostamos nos AVEA, especialmente nas plataformas livres e abertas como o Moodle (Dougiamas e Taylor, 2003). Vislumbramos condições para inovações didático-metodológicas e curriculares em patamares que podem gerar produção de conhecimento científico-tecnológico por meio da criação e compartilhamento sob licenciamento livre e aberto. Pois, em plataformas como o Moodle, existem ferramentas com potencial para desenvolver colaboração, experimentação e criação. Concretamente, a integração de tecnologias educacionais, como os AVEA, estabelece conexão em redes com maleabilidade e escalabilidade suficientes para serem customizados para grupos pequenos ou grandes (Anderson e Dron, 2014). Na comunidade de suporte do Moodle (https://moodle.org/), não há relatos de problemas técnicos em situações que exigem cadastramento de elevados números de participantes com diversidade de perfis. Evidente que as condições de infraestrutura de conexão de Internet, serviços de servidores e suporte de armazenamento em bancos de dados precisam ser planejadas coerentemente com as demandas de cada comunidade virtual ou instituição.

As conexões nas redes são estabelecidas pelos trabalhadores da educação (professores) e os estudantes, de acordo com os níveis de interatividade e interação. Quanto maior a fluência, mais diversas e dinâmicas poderão ser as relações pedagógicas modificando contextos de passividade para ativação. Isso exige saber tomar decisões e participar das mesmas, seja em instâncias primárias, intermediárias ou finais. É dessa maneira que ocorre o entrelaçamento de humanos e não humanos em redes de mediação (Latour, 2001; 2013). A interatividade é requerida para que os conteúdos possam ser manipulados em ações e operações balizadas por objetivos e finalidades educacionais claramente planejadas nos AVEA. A navegabilidade programada interfere no modo como os percursos de estudo são estabelecidos e, por sua vez, nos resultados em termos de aquisição da aprendizagem. Na educação mediada por tecnologias, humanos e não humanos mesclam-se no coletivo (nas redes de conexões possíveis e reformuladas constantemente).

\section{Processo de desenvolvimento e aprimoramento da fluência tecnológico-pedagógica}

A integração das tecnologias em rede e a convergência entre as modalidades requerem 
desenvolvimento e aprimoramento de fluência tecnológico-pedagógica. No âmbito europeu esse condicionante é, muitas vezes, entendido com base no conceito literacia digital (Amante et al., 2015). Esse último, também, não está consolidado entre os pesquisadores. Preferimos o conceito fluência tecnológica criado por Kafai et. al. (1999) por entender que refere-se ao processo de resolução de situações desafiadoras que as tecnologias envolvem. Também, agregamos o conceito pedagógico explicitando interface imediata com modelos teórico-práticos da área educacional.

Conforme Kafai et. al. (1999), não podemos classificar as pessoas que utilizam as tecnologias em "fluente ou não fluente", visto que é um processo longo e contínuo que perpassa pelos ações e operações técnicas, práticas e crítico-emancipatórias. A construção da fluência tecnológico-pedagógica fortalece capacidades de compartilhamento, criação e colaboração em rede. $\mathrm{O}$ aprimoramento da fluência perpassa saberes de funcionamento, os relacionados à ação mediadora e à capacidade de explorar as tecnologias a seu favor e resolver dificuldades inesperadas e indesejadas (Schneider, 2012). Dessa forma, ser fluente requer desenvolvimento da capacidade de utilizar aplicativos, saber explicar como e para qual finalidade utilizamos tais ferramentas, enfim, de aplicar as tecnologias em situações complexas tanto pessoais quanto sociais e profissionais.

Quanto mais desenvolvemos fluência tecnológico-pedagógica, maiores são as conexões hipermidiáticas e as possibilidades de interação dialógico-problematizadora. Assim, desenvolver habilidades contemporâneas, conhecer os conceitos fundamentais e ampliar capacidades intelectuais (Kafai et al. 1999) é essencial para efetivação do compartilhamento de informações, da colaboração livre e aberta em rede, da utilização das máquinas e da sua adaptação. Os conceitos fundamentais referem-se aos conhecimentos de aplicativos básicos necessários para se ter condições de transitar fluentemente, saber como, onde, quando e para que utilizar as tecnologias no ensino-aprendizagem. O desenvolvimento de habilidades contemporâneas exige apropriação das ferramentas tecnológicas em suas diferentes versões, adaptando-se às mudanças. A amplificação de capacidades intelectuais requer (re)criação, no processo ensino-aprendizagem, através das tecnologias e do compartilhamento das inovações. Desse modo, a fluência tecnológico-pedagógica torna-se essencial para operacionalizar a interatividade e gerar interação nos contextos educacionais.

Nesse sentido, ao desenvolver fluência tecnológico-pedagógica, podemos realizar inovações curriculares ao planejar e disponibilizar, recursos e atividades de estudo digitais (livres e abertos como REA) acopladas de modo hipermídia. Assim, o docente aprimora sua fluência e os estudantes a desenvolvem quando realizam a leitura não linear dos recursos, que ocorre através da estruturação hyper com links internos, externos, imagens, sons e vídeos. Além disso, a apropriação dos conceitos e a realização da produção escolar nas atividades de estudo amplificam a fluência tecnológico- 
pedagógica dos estudantes em plataformas digitais. Esse desenvolvimento é fundamental para o planejamento, a implementação, o monitoramento/acompanhamento orientado e a avaliação das potencialidades das ferramentas de recursos e atividades digitais, que podem ser incorporadas na organização dos conteúdos em suas diferentes versões didático-metodológicas.

A integração das tecnologias em rede exige conhecimentos docentes e discentes orientados pelo diálogo-problematizador em torno dos conteúdos curriculares como perspectiva de entendimento, reflexão crítico-emancipatória, ação para re-elaboração de conhecimentos prévios e avanço para compreensão dos conhecimentos científicos. Essa integração tecnológica no processo educacional não é um processo automatizado, pois a fluência pressupõe compreender como as tecnologias funcionam para decidir o que é possível criar com elas. Diante disso, esse processo não é instantâneo nem momentâneo, mas exige estudo e dedicação, disposição para enfrentar desafios e inovar na prática cotidiana.

Em suma, as habilidades contemporâneas, os conceitos fundamentais e as capacidades intelectuais (Kafai et al, 1999) constitui a fluência tecnológico-pedagógica e estão interligados aos conceitos de interatividade e interação dialógico-problematizadora (Schneider, 2012). Assim, docentes e estudantes fluentes lidam com novas tecnologias tendo condições para avaliar, distinguir, aprender, produzir informação e desenvolver conhecimento em rede de modo livre e aberto, como, por exemplo, REA. Isso potencializa desenvolvimento psíquico-intelectual tanto de quem produz e compartilha a produção em rede quanto de quem a reutiliza. Portanto, o aprimoramento de fluência tecnológico-pedagógica qualifica a performance docente na mediação pedagógica, ampliando a integração das tecnologias educacionais em rede e potencializando o processo ensinoaprendizagem.

\section{Design pedagógico para estruturação hipermidiática de recursos e atividades de estudo digitais como REA}

Planejamos, implementamos, monitoramos e avaliamos recursos e atividades de estudo em plataformas digitais com base nos conceitos-chave da Teoria da Rede de Mediadores (Latour, 2001), da Teoria da Atividade (Leontiev, 1978; Davidov, 1988) e da Educação DialógicoProblematizadora (Freire, 1987). O modelo teórico (design pedagógico) explicitado (Figura 1) sistematiza $a$ triangulação conceitual. 


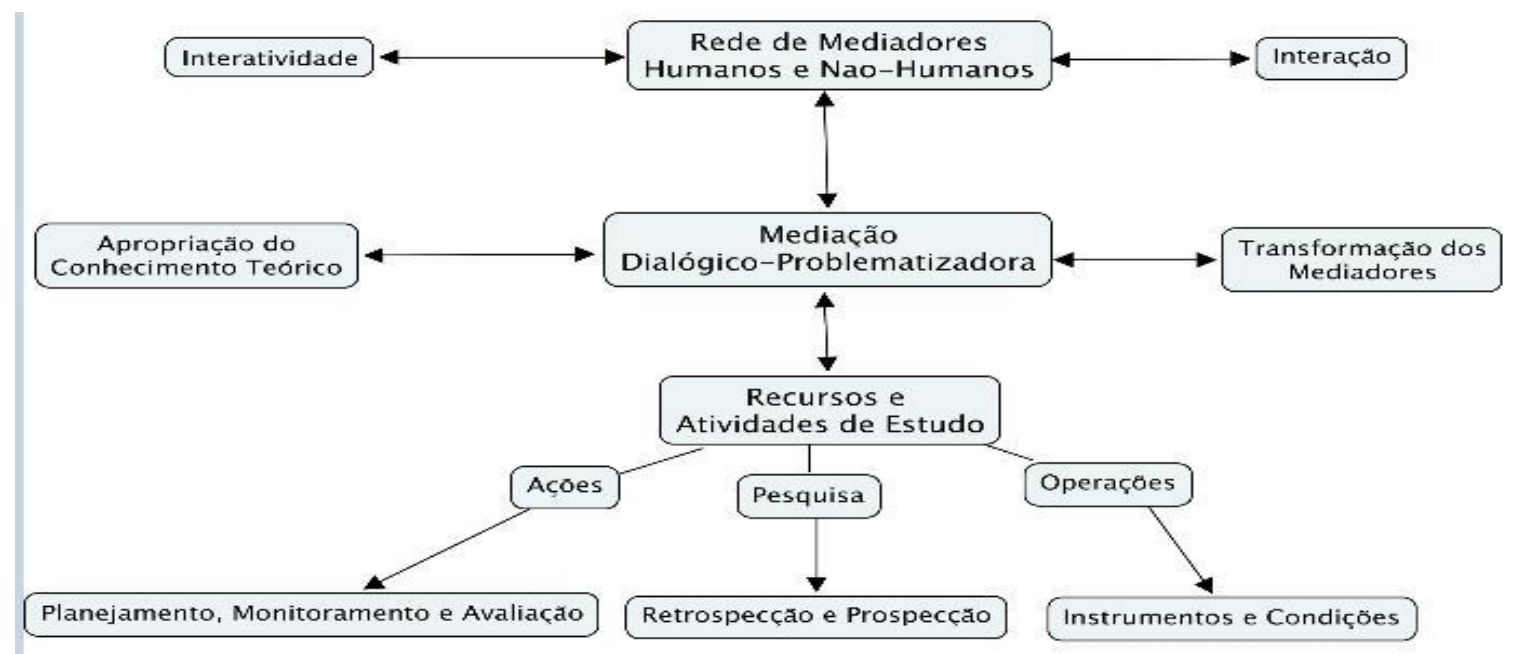

Figura 1 - Modelo Teórico embasado na Teoria da Rede de Mediadores, na Teoria da Atividade de Estudo e na Educação Dialógica-Problematizadora

Fonte: As Autoras

A Teoria da Atividade (Leontiev, 1978) pode ser considerada um desdobramento dos postulados básicos de Vygotsky, especialmente na relação conhecimento-mundo sendo que, essa relação é elaborada historicamente e mediada por instrumentos. Instrumentos são construídos, melhorados, recriados em processos de atividade do ser humano, em especial, a atividade do trabalho. A atividade nos proporciona formas de relação, dirigidas por motivos, ou seja, temos finalidades a serem alcançadas quando estamos em processos de atividade. Orientamo-nos por objetivos e agimos de forma intencional por meio de ações planejadas.

Davidov (1988) incorporou conceitos de Vygotsky, Leontiev e Elkonin para formular uma teoria de ensino desenvolvimental. Para o autor, o sujeito se envolve em diferentes tipos de atividades diariamente. Porém, a atividade principal são as atividades de estudo. Estas orientam os estudantes para a formação científico-tecnológica mediante atividades que impulsionam o desenvolvimento mental através de tarefas (Davidov, 1988).

O autor considera a atividade de estudo como sendo a principal, pois essa tem uma estrutura especial (planejamento, implementação, monitoramento e avaliação), com objetivos (aquisição do pensamento teórico) e finalidades a serem alcançadas (desenvolvimento psíquico-intelectual). Além disso, os conhecimentos teóricos são apresentados em torno de situações-problema. Nesse sentido, o conteúdo da atividade de estudo digital é o conhecimento teórico (problematizado) e, consequentemente, a base do ensino desenvolvimental.

Portanto, na relação ativa, a atividade de estudo se concretiza por meio de ações, operações e tarefas de caráter problemático. Estas são suscitadas por necessidades e motivos. Nessa estrutura, 
o diálogo está colocado como articulador para que esse processo aconteça de forma ativa e crie as necessidades e os motivos para os estudantes desenvolverem a atividade. Podemos dizer que o diálogo constitui o centro organizador da atividade de estudo digital e dele diferentes ações podem surgir a partir da mediação tecnológica.

A Teoria da Rede de Mediadores fortalece esse argumento já que o conceito-chave é o entrelaçamento dos mediadores humanos e não humanos que se mesclam no coletivo. Ambos interferem no desenvolvimento das ações (consequências-objetivos) e operações (Latour, 2001; 2013). As ferramentas não estão dissociadas do humano, pois mediadores não humanos interferem no resultado final da ação humana. As ações dependem das condições que temos para executá-las. Essas condições modificam os próprios objetivos da ação e todos aqueles envolvidos nela. Portanto, esse processo está inter-relacionado. O mediador humano modifica-se à medida que tem a possibilidade de agir sobre a ferramenta e a ferramenta potencializa o processo quando integra a ação. Existe uma relação entre mediadores humanos e não humanos que constituem as redes, os quais, segundo Latour (2001), não são fixos, pois quando se juntam formam uma "proposição nova". Juntos, formarão algo novo (ator híbrido).

Em tempos de mediação tecnológica, disponibilizar as condições para que os estudantes desenvolvam ações perante os conteúdos de aprendizado pode ser extremamente significativo, do ponto de vista psíquico e intelectual. Os mediadores humanos desenvolvem ações e operações modificando-se e, ao mesmo tempo, modificando o seu entorno fazem criações novas, transformando-se. O mediador não humano muda as ações dos mediadores humanos, inclusive o objetivo da ação. Essa composição de diferentes ações gera algo novo e, no caso da educação, esperamos que gere aprendizagem. Esse é o objetivo, quando discorremos sobre o potencial da hipermídia em recursos didáticos digitais. A navegabilidade pela hipermídia permite diferentes ações, escolhas, objetivos. São essas múltiplas possibilidades que podem envolver os estudantes em ações e operações entre o recurso e as atividades de estudo orientados pela diálogo com o professor.

Mediadores não humanos impulsionam uma ação e/ou várias ações. Nesse sentido, oportunizar, criar e disponibilizar mediadores não humanos, apropriando-se de suas potencialidades para despertar curiosidade epistemológica visando à produção de conhecimento científico, é estabelecer interlocução com os princípios freireanos de Educação Dialógico-Problematizadora (Freire, 1987). O diálogo e a problematização são possibilidades transformadoras e possíveis de desenvolvimento histórico, social e cultural dos sujeitos atuantes no processo ensino-aprendizagem. Problematizar e desafiar nas atividades de estudo mediadas por tecnologias, através do diálogo, são maneiras de contextualizar e envolver os estudantes nos temas abordados, nas problematizações a 
serem resolvidas e na busca de estratégias de resolução, procurando sentido e viabilidade do conteúdo de estudo, tornando-o significativo. Mediante essas concepções de ensino-aprendizagem, a mediação pedagógica, sustentada na rede de mediadores humanos e não humanos, é concretizada através da hipermídia nos recursos e nas atividades de estudo digitais em formato REA, potencializando interatividade e interação necessárias à apropriação dos conhecimentos teóricos.

Por isso, enfatizamos a importância da integração de diferentes mídias na produção e na implementação de recursos didáticos digitais, pois com um bom grau de interatividade esses mediadores podem ser utilizados em ambas as modalidades educacionais, estabelecendo, dessa forma, integração e convergência. Para tanto, como destacamos na seção anterior, a fluência tecnológico-pedagógica tecnológica é essencial para produzir e implementar, monitorar e avaliar os recursos e as atividades de estudo. Ressaltamos que a fluência tecnológico-pedagógica consiste na apropriação das tecnologias para desenvolver ensino-aprendizagem e isso requer habilidades para acoplar, de modo hipermidiático nos AVEA, recursos e atividades de estudo e, assim, transformar os mediadores.

As ações de ensinar e aprender ocorrem em tempos didáticos distintos, no entanto, ambas estão interligadas e associadas ao objetivo central do processo: a aquisição de conhecimentos teóricos. Diante disso, o planejamento dos mediadores didáticos precisa estar sustentado no par recursos e atividades de estudo acoplados hipermidiaticamente no AVEA. No momento em que o professor planeja suas ações pedagógicas, mantém a preocupação de traçar caminhos viáveispossíveis para a aquisição de conhecimento teórico, uma vez que o objetivo desse direcionamento é impulsionado pelo motivo gerador (aquisição de conhecimentos teóricos) da atividade de estudo.

Uma atividade de estudo é composta de ações de planejamento, monitoramento e avaliação. Para a realização das ações, as operações são fundamentais, já que elas estabelecem as condições para que os objetivos da atividade de estudo sejam alcançados. Além disso, as atividades de estudo requerem conteúdo dirigido ao objeto, criação e reformulação de elementos. Dessa forma, esperamos como resultado a aquisição do conhecimento teórico e a transformação do sujeito. Ou seja, uma atividade de estudo leva à formação do pensamento teórico assentado na reflexão, na análise e no planejamento mental que conduz ao desenvolvimento psíquico e intelectual.

Nesse sentido, a estruturação dos recursos didáticos hipermidiáticos no AVEA (recursos e atividades de estudo digitais), tanto na educação presencial como na educação a distância, está sustentada na Teoria da Atividade de Estudo, na Rede de Mediadores e na Educação DialógicaProblematizadora. Essa estruturação permite que o conhecimento seja internalizado (abstraído) pelos estudantes, possibilitando subsídios para que eles se apropriem do conhecimento teórico e o 
apliquem em diferentes contextos. Assim sendo, o acoplamento hipermidiático de recursos e atividades de estudo se fortalece na relação entre mediadores humanos e não humanos, os quais podem propiciar interação e interatividade. $\mathrm{O}$ par recursos e atividades de estudo, sustentados na mediação dialógico-problematizadora, potencializa a transformação dos mediadores através da apropriação do conhecimento teórico, por meio de ações e operações que são aprimoradas a partir de resultados de pesquisa.

Portanto, na concepção dialógico-problematizadora, tanto a Teoria da Rede de Mediadores quanto a Teoria da Atividade de Estudo estão diretamente relacionadas com as proposições conceituais de fluência tecnológico-pedagógica e integração e convergência entre as modalidades. Isso porque a ação do mediador humano se modifica (qualifica) quando ocorre com o suporte de ferramentas (mediadores não humanos, como os AVEA) que disponibilizam as condições para o desenvolvimento dos recursos hipermidiáticos e das atividades de estudo. Ao mesmo tempo, as funções das ferramentas se modificam a partir das ações dos mediadores humanos. A transformação dos mediadores humanos se dá a partir da aquisição dos conhecimentos teóricos, requerendo bons índices de fluência tecnológico-pedagógica.

\section{Pesquisa-ação como movimento multidisciplinar retrospectivo e prospectivo}

Os pressupostos teóricos (FIG.1) fundamentam o trabalho multidisciplinar na programação e na implementação (prospecção) e avaliação (retrospecção) do conjunto de REA na DisciplinaExemplo. Propusemos esses REA como solução educacional, inédita e viável, para orientar e otimizar a integração das tecnologias educacionais em rede. Na constituição cíclica do trabalho de pesquisa-ação (Elliott, 1978), avaliamos seu impacto na orientação da performance escolar de professores e estudantes. A pesquisa-ação multidisciplinar (Coutinho, 2008) é realizada por equipe de professores universitários, analistas de sistemas, técnico-administrativos em educação e estudantes universitários. As ações de pesquisa aliadas ao ensino-aprendizagem dos integrantes dessa equipe são baseadas nas decisões advindas de diagnósticos produzidos durante fases de produção de recursos didáticos no Moodle (recursos e atividades de estudo digitais).

Ao longo dos últimos dez anos, temos percebido que os professores universitários se deparam com desafios relativos à fluência em duas dimensões particulares da sua performance: tecnológica e pedagógica. Na ordem técnica e prática da fluência tecnológica, professores universitários levam muito tempo para integrar tecnologias contemporâneas ao processo ensinoaprendizagem porque requer desenvolvimento de habilidades e conceitos sobre o seu uso e funcionamento. Por isso, precisam avaliar com precisão de que modo as tecnologias podem se 
tornar ferramentas úteis para o ensino e o aprendizado dos conteúdos curriculares considerados essenciais.

Quanto à dimensão pedagógica, é recorrente perceber que professores universitários não valorizam as etapas do planejamento e do registro como formas de qualificação da sua performance e a de seus estudantes. Está claro que não é uma questão metodológica apenas. O descompasso entre o que se faz na escolaridade e o que se faz no âmbito sociocultural, mediado pelas tecnologias em rede, é fruto de uma modelização teórico-conceitual assentada no princípio da concentração e da retenção do conhecimento. O processo de ensino centrado na oralidade do professor gera dependência e passividade por parte dos estudantes. Por isso, nossos pressupostos que balizam a pesquisa-ação apontam a possibilidade de aliar as tecnologias contemporâneas ao planejamento e registro das ações e operações. As escolhas advindas das reflexões requerem tomada de decisão.

Para tanto, aliamos aos registros de observações da prática, aos relatórios estatísticos gerados pelo Moodle, a aplicação de questionários tipo survey modelados em escalas likert e organizados por categorias (Babbie, 2005). Destacamos que o próprio Moodle possui ferramentas de diagnóstico que nos permitem realizar pesquisa-ação mediada por tecnologia educacional. É o caso da ferramenta Pesquisa de Avaliação (Dougiamas e Tayloy, 2002) Attitudes Towards Thinking and Learning Survey (ATTLS); Constructivist On-Line Learning Environment Survey (COLLES) e Incidentes Críticos. São pautados pelas perspectiva construtivista e as questões são organizadas nas seguintes categorias: relevância, reflexão crítica, interação, suporte do tutor/professor, apoio dos colegas, compreensão. Entretanto, pelo fato dessas opções de pesquisa de avaliação não permitirem inserção e/ou modificação das questões, optamos pela ferramenta Pesquisa do Moodle. Esta nos permite inclusão de questões mais contextualizadas e tematizadas pelo problema, com vistas a atingir com mais precisão o objetivo de diagnóstico e avaliação. Essa sistemática possibilita análise por triangulação de fontes de dados e procedimentos, conforme exemplo no Quadro 1.

\begin{tabular}{|c|c|c|}
\hline Categoria & Afirmação & Opções de resposta \\
\hline Tecnologias & As ferramentas Recursos e Atividades do & ( ) Discordo Plenamente ( ) Discordo em Parte ( ) \\
\hline Educacionais & Moodle potencializam o desenvolvimento de & Concordo ( ) Concordo em parte ( ) Concordo \\
\hline Hipermídia. & $\begin{array}{l}\text { recursos didáticos e atividades de estudo } \\
\text { digitais organizados de modo hipermídia. }\end{array}$ & Plenamente. \\
\hline
\end{tabular}

Quadro 1: Exemplar de pergunta de um survey implementado na ferramenta questionário do Moodle Fonte - As autoras

Desse modo, sistematizamos o processo para que ele se torne menos dispendioso no que se refere aos aspectos temporais e operacionais das análises e das produção dos relatórios finais. Desenvolvemos e aprimoramos nossa fluência para customizar ferramentas no Moodle a fim de realizar movimento retrospectivo (análise dos avanços e desafios baseada em diagnósticos) e 
prospectivo (planejamentos e implementação de soluções viáveis-possíveis para orientar a prática educacional).

Uma vez explicitada a tipologia teórico-metodológica adotada, a apresentação e a análise dos resultados estão amparadas nas instâncias da observação/registros e da aplicação de questionários survey na edição de um curso de capacitação de professores na Universidade Federal de Santa Maria, Rio Grande do Sul, Brasil, primeiro semestre de 2013. Esse público engloba professores-pesquisadores responsáveis tanto pela elaboração de recursos didáticos e atividades de estudo digitais para cursos a distância quanto aqueles que já integram recursos e atividades de estudo no Moodle como apoio ao ensino presencial.

Esclarecemos que os indicadores desses questionários não são foco de análise específica neste artigo. O propósito é explicitar a ação prospectiva baseada no principal resultado advindo dos diagnósticos: situações-limite na fluência tecnológico-pedagógica dos professores para estruturação didático-metodológica de recursos e atividades de estudo de modo hipermídia no Moodle. A solução viável-possível implementada pela equipe multidisciplinar, para ampliar o impacto e a inovação por meio da integração das tecnologias educacionais, foi a programação do conjunto de REA na Disciplina-Exemplo no Moodle disponível para livre acesso e reutilização. A seguir, apresentamos e analisamos o impacto desses REA como protótipo-guia com funcionalidades gráficas ativadas para navegação de acordo com a orientação didático-metodológica embasada na modelização pedagógica (princípios teórico-práticos) (FIG.1).

\section{Resultados de pesquisa-ação multidisciplinar: programação do conjunto de REA na Disciplina-Exemplo no Moodle}

Os resultados da pesquisa-ação apontam que o Moodle pode ser utilizado no planejamento e na implementação de recursos e atividades de estudo digitais tanto para situações educacionais formais quanto informais. Isso porque possibilita interfaces hipemidiáticas potencializadoras de interatividade e interação colaborativa. Tais ações oportunizam a construção do conhecimento científico-tecnológico necessário ao ensino-aprendizagem em ambientes virtuais. Por isso, programamos os REA na Disciplina-Exemplo no AVEA lançando mão do potencial hipermidiático de suas ferramentas. Esse conjunto de REA foi elaborado na época em que atuamos em equipe multidisciplinar do Núcleo de Tecnologia Educacional (NTE). No momento, está disponível em instalação de Moodle na instituição do Grupo de Pesquisa do CNPq "Investigação-ação e Educação Dialógico-Problematizadora mediadas por tecnologias livres" (http://laveala.proj.ufsm.br/course/view.php?id=58 ). 
A Disciplina-Exemplo é livre e aberta, pois pode ser acessada sem necessidade de login e senha e está licenciado no sistema Creative Commons. Sua estrutura didático-metodológica serve como indicador de orientação pedagógica para planejamento, implementação, monitoramento e avaliação de recursos didáticos hipermídia (recursos e atividades de estudo digitais), em disciplinas mediadas por ferramentas como wikis, fóruns, laboratórios de avaliação, páginas html, etc. Essa solução educacional serve de modelo teórico-prático (design pedagógico) sendo estratégia de orientação e suporte para a estruturação de disciplinas em plataformas virtuais como o Moodle ou outros. Diante disso, o Moodle potencializa integração das tecnologias e convergência entre as modalidades, proporcionando reformulação das práticas pedagógicas e inovação curricular. Por isso, a edição ou a estruturação de disciplinas no AVEA requer orientação e capacitação dos docentes, com o intuito de otimizar o aproveitamento hipermidiático de suas ferramentas para gerar interatividade e interação colaborativa a fim de desenvolver fluência tecnológico-pedagógica.

Em virtude disso, analisamos, neste artigo, o impacto da Disciplina-Exemplo na transposição didática dos conteúdos curriculares no Moodle. Aplicamos a pesquisa tipo survey no Moodle contendo 20 declarações a 52 participantes do Curso de Capacitação Docente, ofertado pelo NTE/UFSM no primeiro semestre de 2013. Obtivemos 31 respostas por livre adesão de uma amostragem não-probabilística, o que corresponde à 52,61\% do total de inscritos. O curso é direcionado tanto a docentes que produzem recursos didáticos e os implementam na modalidade a distância quanto aos que utilizam o AVEA como apoio na modalidade presencial. Para fins de análise, elegemos as 3 declarações que explicitam mais objetivamente as orientações referenciadas no modelo teórico-prático: integração de diferentes mídias no material didático, acoplamento hipermidiático de recursos e atividades de estudo e regularidade no enunciado das atividades de estudo.

Sob essa perspectiva, na declaração explicitada na Figura 2, caracterizamos o Moodle como tecnologia educacional contemporânea potencializadora da integração da hipermídia no material didático. Dos 31 docentes que responderam ao questionário 80,65\% concordam plenamente com essa declaração. Para nós, esse resultado é satisfatório tendo em vista que as ações de capacitação têm como foco a estruturação de disciplinas no AVEA em conformidade com o fomento das política públicas para o ensino-aprendizagem mediado por tecnologias em rede, as quais elucidam a produção hipermidiática de recursos educacionais.

Significa dizer que a ênfase das capacitações está no desenvolvimento de fluência tecnológico-pedagógica. O acoplamento hipermídia dos recursos e atividades de estudo digitais é ação requerida nas políticas públicas para a modalidade a distância. A hipermídia educacional 
potencializa a interatividade com os conteúdos curriculares, estabelecendo caminhos para a interação em rede e a construção colaborativa de conhecimento. A interatividade e a interação estimulam a autonomia, leitura não linear, acesso às informações por associação, diálogoproblematizador em torno dos conteúdos curriculares e reformulação dos conceitos de modo colaborativo.

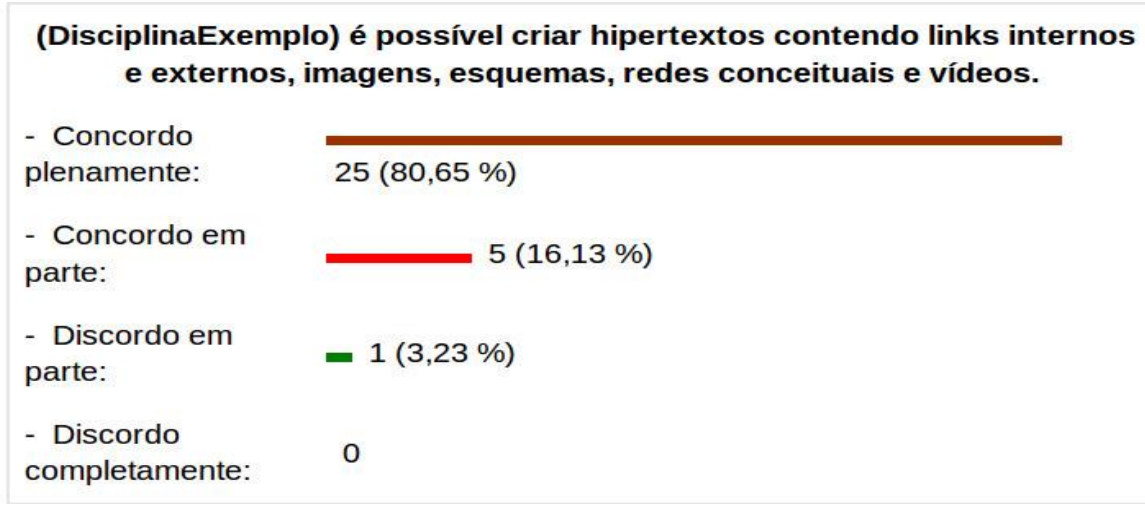

Figura 2- Moodle como tecnologia educacional contemporânea potencializadora de acoplamento hipermídia

Fonte: As autoras. Declaração compilada do questionário survey aplicado.

A organização didático-metodológica dos REA na Disciplina-Exemplo estrutura-se a partir da conexão entre mediadores humanos e não humanos, justamente para otimizar a interatividade e promover, nas atividades de estudo, a interação dialógico-problematizadora. Isso vai ao encontro das políticas públicas no que tange ao potencial interativo requerido nos recursos didáticos. Nesse sentido, quanto aos $16,13 \%$ que apresentam parcialidade na concordância e aos 3,23\% que discordam parcialmente de que é possível, como demonstra a Disciplina-Exemplo, criar recursos didáticos de modo hipermídia no Moodle, podemos aferir que: a) desconhecem o fomento das políticas públicas para o ensino-aprendizagem mediado por tecnologias em rede; b) promovem a cultura da produção impressa; c) possuem pouca fluência tecnológico-pedagógica para operar as ferramentas do Moodle; d) ainda não utilizam o Moodle em suas disciplinas e por isso não exploram as potencialidades de suas ferramentas.

Diante disso, ressaltamos que, para difundir a integração das tecnologias no ensinoaprendizagem visando a convergência entre as modalidades, as ações de capacitação são fundamentais para o desenvolvimento profissional. Por mais que tenhamos obtido 80,65\% de concordância plena, os índices de parcialidade nos preocupam. Isso porque, no contexto do ensinoaprendizagem mediado por tecnologias em rede, o foco é a interatividade para gerar interação em rede. Por isso, a importância de criar hipertextos com conexões a links internos e externos, inserção de imagens, esquemas, redes conceituais e vídeos, para potencializar a dinamicidade do material 
didático e contemplar as características requeridas pela modalidade.

Nesse mesmo viés, enfatizamos a importância do acoplamento hipermidiático de recursos e atividades de estudo (Figura 3) para a aquisição do conhecimento teórico, visto que isso amplia a relação entre ensino-aprendizagem (recursos e atividades). Todavia, apenas 67,74\% dos respondentes concordam plenamente com a declaração. Por mais que esse percentual seja superior aos $50 \%$ do total, leva-nos a refletir sobre qual o entendimento que os docentes possuem sobre acoplamento hipermidiático, uma vez que $32,26 \%$ concordam apenas em parte com essa possibilidade.

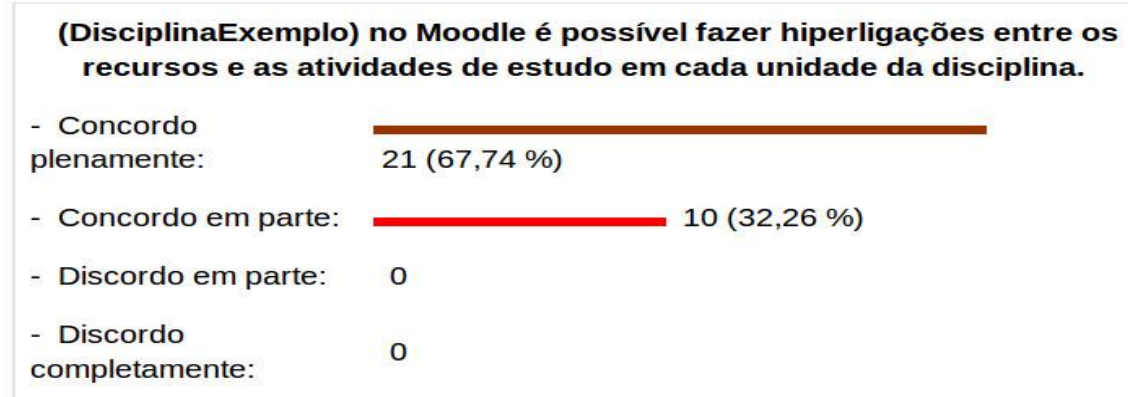

Figura 3 - Acoplamento hipermidiático de recursos e atividades de estudo Fonte: A autoras. Declaração compilada do questionário survey aplicado.

O conjunto de REA na Disciplina-Exemplo contempla, em todas as suas unidades, a hiperligação entre recursos e atividades de estudo. Isso demonstra o potencial hipermídia do Moodle, pois, se não houvesse a possibilidade de fazer link interno dentro do AVEA, não seria permitido acoplar o recurso à atividade de estudo e vice-versa. Nesse sentido, nossa reflexão sobre o resultado obtido centra-se na expansão da proposta de hiperligação entre recursos e atividades de estudo. Novamente, encontramos, nos cursos de capacitação, a solução viável-possível para a problemática em questão. As ações de capacitação docente, tendo como indicador de orientação pedagógica a Disciplina-Exemplo, além de viabilizarem o compreendimento a respeito da importância de hiperligar recursos e atividades de estudo para gerar ensino-aprendizagem em rede, podem potencializar o desenvolvimento de fluência tecnológico-pedagógica para otimizar a prática da interatividade na produção de recursos didáticos no AVEA.

$\mathrm{Na}$ Disciplina-Exemplo, os visitantes podem navegar e visualizar a programação de vários recursos em páginas html, rótulos, sumários, arquivos, bem como acessar um leque variado de enunciados de atividades de estudo colaborativas ou individuais, programadas em ferramentas tarefas, fóruns, lições, glossários, wikis, diários. A proposta concentra-se na possibilidade de oferecer caminhos de navegabilidade hipermidiática que mantêm o acoplamento entre os recursos 
disponibilizados e as atividades de estudo previstas em cada unidade e subunidade, ao longo do semestre letivo. Programamos a ligação hipertextual e semântica entre os recursos (conteúdos curriculares) e as atividades de estudo, pois a aquisição do conhecimento teórico e a produção escolar são práticas indissociáveis e fundamentais à aprendizagem. Ao acoplarmos o recurso à atividade, podemos avaliar a produção do estudante relativa a cada recurso (conteúdo curricular) disponibilizado e, assim, rever os planejamentos conforme os avanços e os obstáculos diagnosticados no decorrer da resolução da atividade de estudo.

Nesse viés, a declaração a seguir (Figura 4) enfatiza a regularidade nos enunciados das atividades de estudo para que os estudantes percebam os objetivos e a finalidade das atividades propostas pelo docente no AVEA. Dos respondentes, 87,10\% concordam plenamente com a referente declaração. Esse desfecho é significativo, pois reafirma a Disciplina-Exemplo como indicador de orientação pedagógica para estruturação de disciplinas no Moodle, uma vez que o modelo teórico-prático mostra claramente regularidade nos enunciados das atividades de estudo. A regularidade permite que o estudante identifique qual é a atividade relativa a cada unidade e subunidade da disciplina, as quais são estabelecidas em conformidade com o Projeto Pedagógico do Curso (PPC) e disponibilizadas semanalmente no Moodle, de acordo com o calendário acadêmico institucional. Ressaltamos ainda que a regularidade e a clareza dos enunciados além de despertarem interesse para a realização das atividades, possibilitam, aos estudantes, a definição de suas rotas de estudo. Enunciados sem regularidade, confusos ou extensos demais dispersam a atenção dos estudantes, dificultando o processo ensino-aprendizagem.

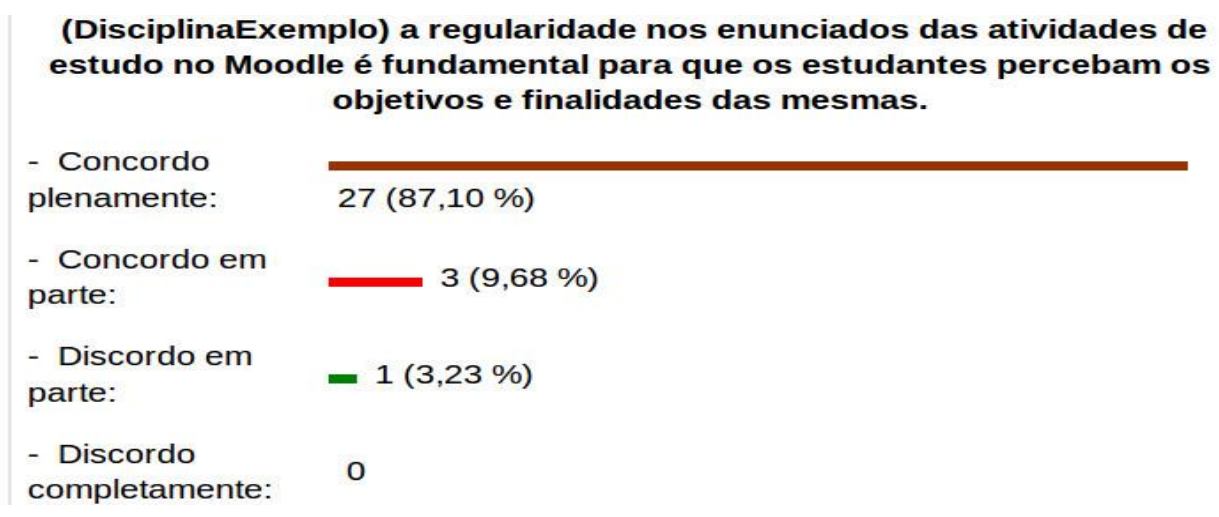

Figura 4 - Potencialidades das ferramentas de atividades de estudo no Moodle Fonte: As autoras. Declaração compilada do questionário survey aplicado.

Apesar de 87,10\% concordarem plenamente com a necessidade de regularidade nos enunciados das atividades de estudo, 9,68\% (que concordam em parte) e 3,23\% (que discordam em parte) ainda não compartilham plenamente da mesma concepção. Desse modo, podemos pensar e 
avaliar que estes docentes posicionam-se de tal forma porque: a) utilizam o Moodle como repositório de recursos dissociados da produção escolar discente; b) não utilizam o Moodle para planejar atividades de estudo; c) não utilizam o Moodle por falta de conhecimento do AVEA; d) ainda não realizaram capacitações e sentem-se inseguros; e) não utilizam a Disciplina-Exemplo como modelo teórico-prático (design pedagógico) para auxiliar no planejamento das atividades de estudo.

Diante desses aspectos elencados, aferimos que a pouca fluência tecnológico-pedagógica de alguns docentes acarreta a não utilização do Moodle e, por consequência, a não compreensão de que a regularidade nos enunciados ajuda na organização das rotinas de estudo do estudante. Além disso, o acoplamento entre recurso e atividade de estudo, em cada unidade e subunidade, vai além da hiperligação tecnológica, pois, possibilita, sobretudo, a associação entre leitura e escrita. Ademais, enunciados claros e objetivos ajudam no desenvolvimento da autonomia do estudante e, consequentemente, na aprendizagem.

Tendo essas afirmativas, constatamos que os REA na Disciplina-Exemplo colaboram ativamente para que tenhamos uma referência a ser seguida no planejamento das atividade de estudo digitais, bem como na regularidade dos seus enunciados. Isso contribui na gestão do processo ensino-aprendizagem, pois possibilita que os estudantes possam se organizar para a realização das atividades e os docentes também tenham uma sequência didático-metodológica a seguir. Visto isso, a ideia-chave da Disciplina-Exemplo no Moodle é apresentar uma solução viávelpossível educacional de orientação tecnológico-pedagógica para potencializar a mediação dialógico-problematizadora.

Ademais, fomentar a produção e compartilhamento de REA nos currículos do ensino superior. Para tanto, a interface entre as ações de planejamento, monitoramento e avaliação está contemplada na estrutura hipermídia dos recursos e das atividades de estudo digitais. Os instrumentos e as condições também são guiados por componentes didáticos como a Apresentação da Disciplina-Exemplo e por um Plano de Ensino que delimita, além dos conteúdos programáticos, objetivos, procedimentos metodológicos, critérios de avaliação, bibliografias e cronograma. Tudo isso está aliado à dinâmica retrospectiva e prospectiva da pesquisa ao se propor a implementação de Pesquisas de Avaliação, tanto no início da disciplina (Expectativas) quanto ao final (Experiência Efetiva).

Para ampliar os níveis de fluência tecnológico-pedagógica na Disciplina-Exemplo, implementamos um Glossário contendo explicações de funcionalidades das ferramentas recursos e atividades do Moodle. Além disso, a solução educacional contém orientações pedagógicas 
indicando potencialidades e finalidades das ferramentas de acordo com os objetivos de ensinoaprendizagem (produção individual ou colaborativa; sincronia ou assincronia). A opção por essa ferramenta justifica-se pela possibilidade de atualização contínua e sistema de busca por palavraschave. Desse modo, configura-se como um tutorial interativo criado no próprio Moodle.

Além disso, em conformidade com o calendário acadêmico institucional, disponibilizamos, na Disciplina-Exemplo, recursos e atividades de estudo digitais ao longo das dezessete semanas letivas previstas. Desse modo, a solução educacional constitui-se como referência de organização didático-metodológica de disciplinas no Moodle. Ao incluirmos, em sua estrutura, apresentação da disciplina, plano de ensino e cronograma de atividades, preocupamo-nos em demonstrar a essencialidade desses itens tanto para a organização das rotinas de estudo dos estudantes quanto para a compreensão do objetivo proposto na disciplina. No decorrer das dezessete semanas, integramos atividades avaliativas (parciais e final), as quais julgamos fundamentais no processo ensino-aprendizagem mediado por tecnologias em rede. Ademais, as políticas públicas fomentam a elaboração de atividades avaliativas presenciais e a distância, a fim de "ajudar o estudante a desenvolver graus mais complexos de competências cognitivas, habilidades e atitudes" (BRASIL, 2007, s.p), diagnosticando os avanços e os obstáculos na aquisição do conhecimento teórico.

Portanto, o conjunto de REA na Disciplina-Exemplo tem gerado impacto e inovação na UFSM, pois muitos professores o consideram uma referência para maximizar a produção hipermídia nos recursos didáticos digitais nos cursos em que atuam. Para implementar design pedagógico inovador no Moodle, é preciso saber operar com as ferramentas de recursos e atividades explorando os formulários de edição que permitem inserir imagens, links internos e externos, incorporar arquivos de vídeo e/ou áudio, formatar fontes e estilos, entre outros. Do ponto de vista da implementação de soluções para orientar as operações de interatividade no Moodle, a DisciplinaExemplo comporta-se como produto tutorial. Ou seja, serve como instrumento (template) melhorando as condições para compreensão do que é possível; a) criar de modo hipermidiático; b) como compartilhar produções didáticas de modo livre e aberto; c) inovar mediados pela tecnologia educacional contemporânea (requisito fundamental da fluência tecnológico-pedagógica).

\section{Conclusão}

Mencionamos que as ações da equipe multidisciplinar são direcionadas com foco no acoplamento hipermidiático de recursos e atividades de estudo digitais, sustentadas nos resultados de pesquisa-ação. Portanto, no decorrer deste artigo, analisamos o impacto da utilização do Moodle como tecnologia contemporânea para criar um conjunto de REA, abordamos os conceitos-chave das 
teorias-guia (design pedagógico como modelo teórico-prático), explicitamos os procedimentos metodológicos da pesquisa-ação e apresentamos a programação da Disciplina-Exemplo no Moodle como resultado (solução educacional viável-possível) gerada na equipe multidisciplinar da UFSM.

A programação hipermídia de recursos e atividades de estudo digitais como conjunto de REA na Disciplina-Exemplo no Moodle foi orientada pelo modelo teórico-prático sustentado nos conceitos-chave da Teoria da Rede de Mediadores, da Teoria da Atividade de Estudo e na Educação Dialógico-Problematizadora. A produção escolar mediada pelo Moodle institucional amplia a integração de tecnologias educacionais contemporâneas e convergência das modalidades na UFSM. Para tanto, o trabalho multidisciplinar de pesquisa, desenvolvimento e capacitação tem sido orientado com foco na melhoria da fluência tecnológico-pedagógica dos mediadores humanos envolvidos nos processos ensino-aprendizagem tanto presenciais quanto a distância.

Desse modo, dentre as metas e ações de capacitação previstas planejamos a produção de recursos didáticos livres e abertos para consolidar o movimento REA na instituição. Assim, poderemos avançar na compreensão do impacto da estrutura didático-metodológica configurada por meio do acoplamento hipermidiático dos recursos e atividades de estudo digitais. Esse foco na capacitação sempre cria condições para que os professores operem com mais fluência as ferramentas digitais ao planejar, implementar, monitorar e avaliar.

Dessa forma, o conjunto de REA na Disciplina-Exemplo serve como referencial que pode consolidar e ampliar a fluência tecnológico-pedagógica contemporânea maximizando interatividade nos conteúdos curriculares e interação em ambientes virtuais de ensino-aprendizagem institucionais. Além disso, otimiza o trabalho multidisciplinar, pois a criação de modelizações ajuda a representar materialmente a situação didática em questão. Mediar as situações de ensino-aprendizagem pelas tecnologias educacionais contemporâneas é uma atividade cognitiva que exige decisões do professor tanto em termos dos conteúdos quanto dos procedimentos metodológicos. Por isso, o professor ao compreender o modelo hipermidiático proposto, percebe a estrutura didáticometodológica que o perpassa e pode se orientar pelo mesmo.

Do ponto de vista prospectivo, vislumbramos o trabalho multidisciplinar em torno da ampliação das orientações no Glossário (tutorial interativo no Moodle), bem como o desenvolvimento de tutoriais sobre as ferramentas de atividades novas que foram incorporadas com a atualização da versão do Moodle na UFSM. Além disso, ampliar a elaboração e o compartilhamento livre e aberto de novos recursos pode estabelecer critérios operacionais para orientar programas de educação aberta. 


\section{Referências}

AMANTE, L. G. E et al. (2015). Literacia Digital: o módulo de ambientação online na Universidade Aberta. In: Anais Challenges 2015: Meio Século de TIC na Educação, Half a Century of ICT in Education, Braga.

Amiel, T. (2013). Educação aberta: configurando ambientes, práticas e recursos educacionais. Em B. Santana, C. ROSSINI e N. D. L. Pretto (Org.). Recursos Educacionais Abertos: práticas colaborativas. Disponível em http://www.livrorea.net.br/livro/home.html

ANDERSON, T. e DRON, J. (2014). Teaching Crowds Learning and Social Media. AU Press, Athabasca University.

BABBIE, E. (2005). Métodos de Pesquisas de Survey. Tradução de Guilherme Cezarino. $3^{\mathrm{a}}$ ed. Editora UFMG: Belo Horizonte.

BRASIL, MEC. (2007). Secretaria de Educação a Distância. Referenciais de Qualidade para Educação Superior a Distância. MEC/SEED: Brasília, DF, 2007. Disponível em <http://portal.mec.gov.br/seed/indexaroption=com_content\&task=view\&id=248\&Itemid=42> (acesso em 21 maio de 2015).

Butcher, N., Kanwar, A. e Uvalic'-Trumbic', S. (2011). A Basic Guide to Open EducationalResources (OER). Vancouver: Commonwealth of Learning.

CASTELLS, M. (1999). A sociedade em rede. A era da informação: economia, sociedade e cultura. São Paulo: Paz e Terra.

COUTINHO, C. (2008). Investigação-ação: metodologia preferencial nas práticas educativas. 2008. Disponivel em <http://faadsaze.com.sapo.pt/indice.htm> (acesso em 29 de maio de 2015).

DAVIDOV, V. (1988). La Enseñanza Escolar y el Desarollo Psíquico: Investigación psicológica teórica y experimental. Moscu: Editorial Progresom.

DOUGIAMAS, M. e TAYLOR, P. C. (2002). Interpretive analysis of an internet-based course constructed using a new courseware tool called Moodle. HERDSA. Disponível em <http://dougiamas.com/writing/herdsa2002/> (acesso em 29 maio de 2015).

DOUGIAMAS, M. e TAYLOR, P. C. (2003). Moodle: Using Learning Communities to Create an Open Source Course Management System. In: EDMEDIA. Disponível em $<$ http://dougiamas.com/writing/edmedia2003/> (acesso em 29 de maio de 2015).

ELLIOT, J. (1978). What is Action-Research in Schools? In the Action Research eader, p.121-122.

Deaking University Production Unit. Third edition. Australia: Deakin University Printey.

FREIRE, P. (1987). Pedagogia do oprimido. Rio de Janeiro: Paz e Terra, 1987.

FREIRE, P. (1982). Ação cultural para a liberdade e outros escritos. Rio de Janeiro, Paz e Terra.

FREIRE, P. (1989). Educação como prática de liberdade. Rio de Janeiro: Paz e Terra. 
KAFAI, Y. et al. (1999). Being Fluent with Information Technology.1999. Disponível em <http://www.nap.edu/catalog/6482.html> (acesso em 15 maio de 2015).

LATOUR, B. (2001). A esperança de Pandora: ensaios sobre a realidade dos estudos científicos. Tradução de Gilson César Cardoso do Sousa. Bauru, SP: EDUSC.

LATOUR, B. (2013) Redes, sociedades, esferas: reflexões de um teórico ator-rede. Informática na Educação: teoria e prática. Porto Alegre, v. 16, n. 1, p. 23-36, jan./jun. 2013.

SCHNEIDER, D. da R. (2012). Prática dialógico-problematizadora dos tutores na UAB/UFSM: fluência tecnológica no Moodle. (Dissertação de Mestrado). Mestrado em Educação. Universidade Federal de Santa Maria: Santa Maria.

TAPSCOTT, D. e WILLIAMS, A. D. (2007). Wikinomics: como a colaboração em massa pode mudar o seu negócio. Tradução de Marcello Lino. Rio de Janeiro: Nova Fronteira.

UNESCO (2011). Recursos Educacionais Abertos. Commonwealthof Learning com colaboração da ComunidadeREA-Brasil. Disponível em http://rea.net.br/site/o-que-e-rea/ (acesso em 25 de maio de 2015).

Recebido em: 01.06.2016

Aceito em: 08.08.2017 